
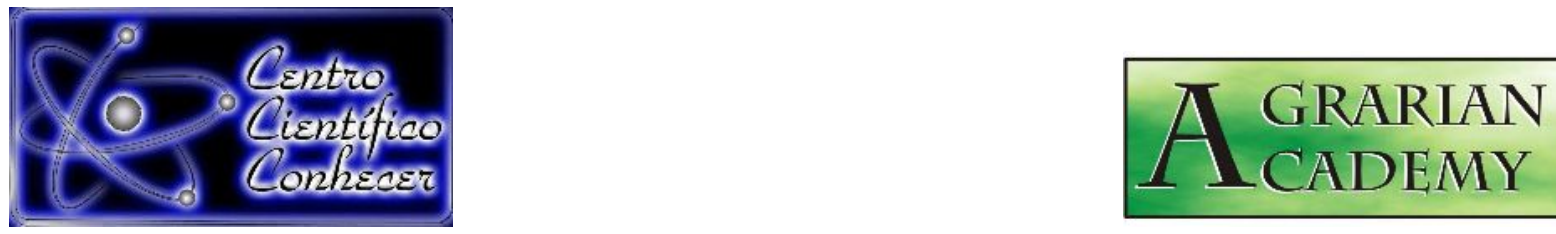

\title{
EFEITO DO ESTÁDIO DE DESENVOLVIMENTO E DOSES DE HERBICIDA NA SUPRESSÃO DE CRESCIMENTO DE UROCHLOA RUZIZIENSIS
}

Gilmarcos de Carvalho Corrêa ${ }^{1}$, Breno Pinto Resende Melo ${ }^{2}$, Evandro Macedo de Freitas $^{2}$, Ailton José Crispim Filho ${ }^{3}$, Luís Carlos Cunha Júnior ${ }^{1}$

${ }^{1}$ Professor Doutor da Escola de Agronomia da Universidade Federal de Goiás UFG, Goiânia-GO, Brasil (gilmarcoscorrea@gmail.com).

${ }^{2}$ Consultor Técnico da Agroquima Produtos Agropecuários Ltda., Goiânia-GO, Brasil.

${ }^{3}$ Doutorando do Programa de Pós-Graduação em Genética e Melhoramento de Plantas - PPGM da Escola de Agronomia da UFG, Goiânia-GO, Brasil.

Recebido em: 02/06/2019 - Aprovado em: 15/06/2019 - Publicado em: 22/07/2019 DOI: 10.18677/Agrarian_Academy_2019a14

\section{RESUMO}

Este trabalho objetivou avaliar doses do herbicida glifosato para a supressão do desenvolvimento da forrageira Urochloa ruziziensis (Sin. Brachiaria ruziziensis) nos estádios de um e dois perfilhos, em sistema de integração lavoura-pecuária com milho resistente ao herbicida glifosato. Os tratamentos foram testemunha sem pulverização e glifosato nas doses de $18 \mathrm{~g}$ e.a.ha ${ }^{-1}$ e $36 \mathrm{~g}$ e.a.ha ${ }^{-1}$ para forrageira no estádio de um perfilho e testemunha sem pulverização e glifosato nas doses de $54 \mathrm{~g}$ e.a.ha ${ }^{-1}$ e $72 \mathrm{~g}$ e.a.ha ${ }^{-1}$ para forrageira no estádio de dois perfilhos. Os resultados mostraram que as doses testadas não reduziram o perfilhamento da forrageira nos dois estádios de desenvolvimento estudados. As doses testadas reduziram a altura de plantas da forrageira em ambos os estádios de desenvolvimento e glifosato a 36 $\mathrm{g}$ e.a.ha ${ }^{-1}$ apresentou o maior efeito na redução da altura de plantas no estádio de 1 perfilho. As doses de $54 \mathrm{~g}$ e.a.ha ${ }^{-1}$ e $72 \mathrm{~g}$ e.a.ha ${ }^{-1}$ de glifosato reduziram, igualmente, a altura de plantas no estádio de 2 perfilhos.

PALAVRAS-CHAVE: Brachiaria ruziziensis, glifosato, integração lavoura pecuária.

\section{EFFECT OF DEVELOPMENT STAGE AND HERBICIDE DOSES IN UROCHLOA RUZIZIENSIS GROWTH SUPRESSION}

\begin{abstract}
The aiming of study was to evaluate glyphosate herbicide doses for development suppression of Urochloa ruziziensis (Syn. Brachiaria ruziziensis) forage in one and two tillers stage in crop livestock integration with glyphosate resistant maize.. Treatments were no sprayed control and glyphosate at doses 18 g.ha ${ }^{-1}$ a.e. and 36 g.ha ${ }^{-1}$ a.e. in one tiller forage stage and no sprayed control and glyphosate at doses 54 g.ha ${ }^{-1}$ a.e. and 72 g.ha $^{-1}$ a.e. in two tillers forage stage. Results showed no reduction in forage tillering at two evaluated development stages. Tested doses AGRARIAN ACADEMY, Centro Científico Conhecer - Goiânia, v.6, n.11; p. 145 2019
\end{abstract}


reduced forage plants height for both development stages. Glyphosate at $36 \mathrm{~g}$.ha $\mathrm{h}^{-1}$ a.e. presented most effect in plants height reduction in 1 tiller stage. Glyphosate doses $54 \mathrm{~g}$ e.a.ha ${ }^{-1}$ and $72 \mathrm{~g}$ e.a.ha ${ }^{-1}$ equally reduced plants height in 2 tillers stage.

KEYWORDS: Brachiaria ruziziensis, crop-livestock integration, glyphosate.

\section{INTRODUÇÃO}

O sistema de integração lavoura pecuária caracteriza-se pela produção consorciada de grãos, especialmente milho, milheto, sorgo e soja, com forrageiras tropicais de grande potencial de desenvolvimento, principalmente do Gênero Urochloa (Sin. Brachiaria), tanto em sistema de plantio direto (SPD) quanto em sistema de plantio convencional, com produção de grãos e concomitante formação da pastagem, conforme Dias et al. (2018) e Santos et al. (2018).

A implementação desse sistema de consórcio representa uma alternativa de manejo que propicia maior racionalidade na utilização dos recursos de produção, inclusive tempo, além de reduzir a infestação de plantas daninhas (ABBAS et al., 2018; TIMOSSI et al., 2018). A competição por fatores de desenvolvimento entre cultura e forrageira irá ocorrer, com consequente escassez de fatores de desenvolvimento, sendo necessário equilibrar-se as capacidades competitivas das espécies consorciadas com a supressão do desenvolvimento da forrageira com uso de herbicidas (FRANCHINI et al., 2015; SILVA et al., 2016).

O plantio consorciado de milho e gramíneas forrageiras do Gênero Urochloa constitui-se uma das melhores opções de integração devido à elevada eficiência metabólica das espécies cultivadas e excelente adaptação das forrageiras às condições edafoclimáticas da Região Centro Oeste, usando-se, basicamente, até há alguns anos, as forrageiras Urochloa brizantha e Urochloa decumbens como culturas de cobertura e o herbicida nicosulfuron, largamente utilizado, como produto padrão na supressão da forrageira (FERREIRA et al., 2007; SILVA et al., 2014; FREITAS et al., 2015).

Mais recentemente, tem crescido o interesse dos produtores pelo cultivo consorciado de milho resistente ao herbicida glifosato, com evento de transgenia, associado à espécie Urochloa ruzizienis e tendo-se o herbicida glifosato, do grupo dos inibidores de EPSPs (enzima enol-piruvil-shiquimato-fostato-sintase) como ferramenta de supressão da forrageira como alternativa ao herbicida padrão nicosulfuron do grupo dos inibidores de ALS (enzima aceto-lactato-sintase), conforme relataram Vidal et al. (2014), Silveira et al. (2017), Rodrigues e Almeida (2018) e São Miguel et al. (2018).

Esse consórcio aliaria uma espécie com ótimas características como forrageira e planta de cobertura a uma cultura resistente ao herbicida de manejo, o que possibilitaria diversificação de princípio ativo e mecanismo de ação do produto, além de boa eficiência do glifosato na supressão ou dessecação da forrageira para pastagem ou palhada (JASPER et al., 2015; QUEIROZ et al., 2016; MACHADO et al., 2018).

O objetivo deste trabalho foi determinar o melhor estádio de desenvolvimento e a melhor dose do herbicida glifosato para a supressão da forrageira Urochloa ruziziensis em sistema de integração lavoura pecuária com milho resistente ao herbicida. 


\section{MATERIAL E MÉTODOS}

O experimento foi conduzido na área experimental da Escola de Agronomia da Universidade Federal de Goiás em Goiânia-GO com o plantio das culturas no dia 30/03/2018. As coordenadas geográficas locais são $16^{\circ} 44^{\prime}$ S Latitude e 49 $44^{\prime} \mathrm{W}$ Longitude e $749 \mathrm{~m}$ de altitude. O clima é classificado como Tropical Semi Úmido (Köppen) e o solo é classificado como Latossolo Vermelho, típico do ambiente do cerrado e suas principais características físico-químicas constam da Tabela 1.

TABELA 1. Características físico-químicas do Latossolo Vermelho na determinação de doses de glifosato na supressão de Urochloa ruziziensis em consórcio com milho resistente ao herbicida. Goiânia-GO. 2018.

\section{CARACTERISTICAS FISICO-QUÍMICAS}

\begin{tabular}{|c|c|c|c|c|c|}
\hline $\begin{array}{c}\mathrm{pH} \\
\left(\mathrm{CaCl}_{2}\right)\end{array}$ & & $\mathrm{Ca}^{2}$ & $\begin{array}{l}\mathrm{Mg} \\
\mathrm{mol} / \mathrm{c}\end{array}$ & $\begin{array}{l}+\mathrm{K}^{+} \\
\left.\mathrm{m}^{3}\right)\end{array}$ & \\
\hline 6,0 & 0,0 & 2,9 & 1,4 & 0,33 & 6,2 \\
\hline
\end{tabular}

M.O.= matéria orgânica; S.B.= saturação de bases; Arg.= argila.

O plantio da forrageira Urochloa ruziziensis cv. Ruziziensis foi realizado a lanço na quantidade de $15 \mathrm{Kg} \cdot \mathrm{ha}^{-1}$ de sementes com $90,1 \%$ de pureza, $85 \%$ de viabilidade e valor cultural (VC) igual a 76, incorporadas com grade niveladora. Em seguida, foi realizado o plantio do híbrido de milho 2B688PW, resistente a glifosato, com semeadora em linhas espaçadas de $0,45 \mathrm{~m}$, sendo as sementes de milho colocadas a $5 \mathrm{~cm}$ de profundidade, obtendo-se estande de 60.000 plantas de milho por hectare.

A adubação foi realizada para suprir as exigências da cultura do milho e foram fornecidos $120 \mathrm{Kg} \cdot \mathrm{ha}^{-1}$ de $\mathrm{N}_{2}, 60 \mathrm{Kg} \cdot \mathrm{ha}^{-1}$ de $\mathrm{P}_{2} \mathrm{O}_{5}$ e $57 \mathrm{Kg}$ ha ${ }^{-1}$ de $\mathrm{K}_{2} \mathrm{O}$. A irrigação foi feita com aplicação de lâmina de água de $3 \mathrm{~mm}$ do plantio até o final das determinações nas plantas da forrageira.

Os tratamentos (doses do herbicida) foram aplicados aos 20 e 25 dias após o plantio das culturas, com a forrageira no estádio inicial de 1 ou 2 perfilhos e o milho no estádio vegetativo V5. Assim, foram considerados dois experimentos independentes para cada estádio de desenvolvimento das plantas no ato da aplicação do herbicida (se 1 ou 2 perfilhos). As pulverizações foram feitas com equipamento costal a $\mathrm{CO}_{2}$ à pressão de $200 \mathrm{KPa}$, com barra de pulverização com dois bicos planos TeeJet 80.02 VS, regulado para aplicar 200 L.ha $^{-1}$ de calda de pulverização.

Avaliaram-se as plantas da forrageira, aos 5, 10 e 15 dias após aplicação (DAA) do herbicida, quanto a número de perfilhos e altura de plantas $(\mathrm{cm})$ do colo à extremidade da folha mais longa. As parcelas, dispostas de forma contínua nos blocos, foram constituídas de 4 linhas, espaçadas de $0,45 \mathrm{~m}$, com $4 \mathrm{~m}$ de comprimento, totalizando $5,4 \mathrm{~m}^{2}$ de área total. Adotaram-se bordaduras de $0,225 \mathrm{~m}$ nas laterais e $0,5 \mathrm{~m}$ nas extremidades, totalizando $2,7 \mathrm{~m}^{2}$ de parcela útil.

Os experimentos foram conduzidos em delineamento de blocos casualizados em esquema fatorial $3 \times 3$, consistindo em três doses de glifosato para cada estádio de desenvolvimento $\left(0 \mathrm{~g}\right.$ e.a.ha ${ }^{-1}, 18 \mathrm{~g}$ e.a.ha ${ }^{-1}$ e $36 \mathrm{~g}$ e.a.ha ${ }^{-1}$ : um perfilho e $0 \mathrm{~g}$ e.a.ha- ${ }^{-1}, 54 \mathrm{~g}$ e.a.ha ${ }^{-1}$ e $72 \mathrm{~g}$ e.a.ha ${ }^{-1}$ : dois perfilhos) e três épocas de avaliação (5 DAA, 10 DAA e 15 DAA), com cinco repetições. Os dados foram analisados com o auxílio do programa estatístico $R$ (CORE TEAM, 2018). 


\section{RESULTADOS E DISCUSSÃO}

As análises de variância dos dados demonstraram diferenças significativas entre as doses de glifosato para altura de plantas com aplicação em um perfilho e número de perfilhos e altura de plantas no estádio de dois perfilhos. As interações entre doses e dias após aplicação ( $D \times T)$ foram significativas apenas para número de perfilhos no primeiro estádio de desenvolvimento e apenas para altura de plantas na aplicação em estádio de dois perfilhos (Tabela 2).

TABELA 2. Resumo das análises de variância para número de perfilhos e altura de plantas $(\mathrm{cm})$ de Urochloa ruziziensis submetidas, no estádio de 1 perfilho, ao herbicida glifosato nas dosagens de $0 \mathrm{~g}$ e.a.ha ${ }^{-1} ; 18 \mathrm{~g}$ e.a.ha ${ }^{-1}$ e $36 \mathrm{~g}$ e.a.ha ${ }^{-1}$ e, no estádio de 2 perfilhos, nas dosagens de $0 \mathrm{~g}$ e.a.ha ${ }^{-1} ; 54 \mathrm{~g}$ e.a.ha ${ }^{-1}$ e $72 \mathrm{~g}$ e.a.ha ${ }^{-1}$, avaliadas em 3 épocas (5, 10 e 15 DAA) em consórcio com milho resistente ao herbicida. Goiânia-GO. 2018.

\begin{tabular}{|c|c|c|c|}
\hline \multicolumn{4}{|c|}{1 perfilho $(0,50$ e $100 \mathrm{ml}$ p.c.) } \\
\hline \multirow{2}{*}{ F.V. } & \multirow{2}{*}{ GL } & \multicolumn{2}{|c|}{ Quadrados médios } \\
\hline & & Número de Perfilhos & Altura de Plantas $(\mathrm{cm})$ \\
\hline Repetições & 4 & 0,0476 & 3,4739 \\
\hline Dias (D) & 2 & $37,1432^{* *}$ & $1096,18^{\star *}$ \\
\hline Tratamentos $(\mathrm{T})$ & 2 & $0,1732^{\text {ns }}$ & $1281,45^{\star \star}$ \\
\hline$D^{*} \mathrm{~T}$ & 4 & $1,2361^{* *}$ & $10,95^{\text {ns }}$ \\
\hline Resíduo & 32 & 0,0999 & 7,39 \\
\hline Média & & 3,157 & 39,0278 \\
\hline \multirow[t]{2}{*}{ CV\% } & & 10,01 & 6,97 \\
\hline & \multicolumn{3}{|c|}{2 perfilhos $(0,150$ e $200 \mathrm{ml}$ p.c. $)$} \\
\hline \multirow{2}{*}{ F.V. } & \multirow{2}{*}{$\mathrm{GL}$} & \multicolumn{2}{|c|}{ Quadrados médios } \\
\hline & & Número de Perfilhos & Altura de Plantas $(\mathrm{cm})$ \\
\hline Repetições & 4 & 0,15075 & 3,13 \\
\hline Dias (D) & 2 & $0,33921^{*}$ & $12,91^{\text {ns }}$ \\
\hline Tratamentos $(\mathrm{T})$ & 2 & $0,50971^{* *}$ & $114,2403^{\star *}$ \\
\hline$D^{*} T$ & 4 & $0,16441^{\mathrm{ns}}$ & $10,6258^{\star *}$ \\
\hline Resíduo & 32 & 0,09004 & 16,23 \\
\hline Média & & 3,440 & 44,61 \\
\hline CV\% & & 8,72 & 9,03 \\
\hline
\end{tabular}

A Tabela 3 mostra os resultados para plantas da forrageira Urochloa ruziziensis no estádio de 1 (um) perfilho, submetidas a três doses de glifosato e avaliadas aos 5, 10 e 15 dias após aplicação (DAA) quanto a número de perfilhos e altura de plantas.

Aos 5 DAA verificou-se para a variável número de perfilhos que os tratamentos T2 (glifosato a $18 \mathrm{~g}$ e.a.ha ${ }^{-1}$ ) e T3 (glifosato a $36 \mathrm{~g}$ e.a.ha ${ }^{-1}$ ) diferiram da testemunha não pulverizada (T1) e foram iguais entre si, apresentando menor perfilhamento que as parcelas não pulverizadas. Para a variável altura de plantas os tratamentos T2 e T3 diferiram da testemunha T1 e entre si, com a maior dose de glifosato (36 g e.a.ha ${ }^{-1}$ ) apresentando maior redução na altura das plantas (Tabela 3)

Os resultados demonstraram a grande sensibilidade de Urochloa ruziziensis a glifosato conforme relataram Brighenti et al. (2011) e Silveira et al. (2017) que AGRARIAN ACADEMY, Centro Científico Conhecer - Goiânia, v.6, n.11; p. 148 2019 
testaram a resposta a glifosato de Urochloa ruziziensis em estudos de dessecação a doses variando de 90 a $2.275 \mathrm{~g}$ e.a.ha ${ }^{-1}$, aplicadas na forrageira em estádios de desenvolvimento bem mais adiantados, entre 50 e 160 dias após semeadura . No presente estudo as doses usadas foram bem mais baixas, contudo aplicadas entre 20 e 25 dias após semeadura o que explicaria sua eficiência.

A supressão do perfilhamento de Urochloa ruziziensis já aos 5 DAA mostra um efeito mais rápido que o reportado por Costa et al. (2013) e Machado et al. (2018) que observaram boa eficiência de glifosato na supressão de perfilhos desta forrageira apenas aos 14 DAA para plantas dessecadas para formação de palhada.

TABELA 3. Comparação de médias dos tratamentos para as variáveis número de perfilhos e altura de plantas $(\mathrm{cm})$ de Urochloa ruziziensis submetidas, no estádio de 1 (um) perfilho, ao herbicida glifosato nas dosagens de $0 \mathrm{~g}$ e.a.ha ${ }^{-1} ; 18 \mathrm{~g}$ e.a.ha ${ }^{-1} \mathrm{e}$ $36 \mathrm{~g}$ e.a.ha ${ }^{-1}$, avaliadas em 3 épocas (5, 10, 15 DAA) em consórcio com milho resistente ao herbicida. Goiânia-GO. 2018.

\begin{tabular}{|c|c|c|}
\hline \multicolumn{3}{|c|}{5 DAA } \\
\hline Tratamentos & \multicolumn{2}{|c|}{ Variáveis } \\
\hline & Número de Perfilhos & Altura de Plantas (cm) \\
\hline T1 (testemunha) & $1,88 \mathrm{a}$ & $38,80 \mathrm{a}$ \\
\hline T2 (glifosato 18 g e.a.ha ${ }^{-1}$ ) & $1,04 \mathrm{~b}$ & $28,30 \mathrm{~b}$ \\
\hline T3 (glifosato 36 g e.a.ha ${ }^{-1}$ ) & $1,12 b$ & $23,10 \mathrm{c}$ \\
\hline
\end{tabular}

10 DAA

\begin{tabular}{lcc}
\hline Tratamentos & \multicolumn{2}{c}{ Variáveis } \\
\hline & Número de Perfilhos & Altura de Plantas (cm) \\
\cline { 2 - 3 } T1 (testemunha) & $3,72 \mathrm{a}$ & $49,35 \mathrm{a}$ \\
T2 (glifosato 18 g e.a.ha ${ }^{-1}$ ) & $4,10 \mathrm{a}$ & $38,90 \mathrm{~b}$ \\
T3 (glifosato 36 g e.a.ha $\left.{ }^{-1}\right)$ & $3,95 \mathrm{a}$ & $31,52 \mathrm{c}$ \\
\hline
\end{tabular}

\section{DAA}

Tratamentos Variáveis

\begin{tabular}{lcc} 
& Número de Perfilhos & Altura de Plantas $(\mathrm{cm})$ \\
\cline { 2 - 3 } T1 (testemunha) & $3,65 \mathrm{~b}$ & $58,60 \mathrm{a}$ \\
T2 (glifosato 18 g e.a.ha ${ }^{-1}$ ) & $4,70 \mathrm{a}$ & $45,48 \mathrm{~b}$ \\
T3 (glifosato 36 g e.a.ha $^{-1}$ ) & $4,25 \mathrm{a}$ & $37,20 \mathrm{c}$
\end{tabular}

Médias seguidas de mesma letra dentro da mesma data de avaliação não diferem entre si pelo teste de Tukey a $5 \%$ de probabilidade.

A rápida resposta da forrageira ao glifosato na supressão do perfilhamento e altura de plantas, mesmo em sua menor dose (18 g e.a.ha $\left.{ }^{-1}\right)$, poderia, também, ser atribuída ao fornecimento de água, via irrigação, o que segundo Machado et al. (2018) aumentaria a sensibilidade de Urochloa ruziziensis ao glifosato quando comparada à plantas sujeitas a eventuais déficits hídricos.

Aos 10 DAA a avaliação de plantas da forrageira no estádio de 1 perfilho, quanto ao número de perfilhos produzidos, demonstrou que os tratamentos T2 e T3 não diferiram da testemunha $\mathrm{T} 1$ e não induziram efeito supressor sobre 0 perfilhamento da forrageira, o que poderia indicar o uso de doses insuficientes para manter o efeito supressor sobre o perfilhamento da forrageira (Tabela 3).

Para a variável altura de plantas observou-se a manutenção do efeito inicial observado na primeira avaliação com inibição de altura de plantas proporcional à AGRARIAN ACADEMY, Centro Científico Conhecer - Goiânia, v.6, n.11; p. 149 2019 
dose aplicada (Tabela 3). Os resultados indicaram que as doses mostraram-se mais efetivas na supressão da altura de plantas que no número de perfilhos da forrageira. Estes resultados coincidem, parcialmente, com os observados por Brighenti et al. (2011) que relataram maior suscetibilidade de Urochloa ruziziensis ao glifosato, aos 7 DAA que aos 14 DAA, na redução do desenvolvimento das plantas.

Aos 15 DAA as plantas no estádio de desenvolvimento de 1 perfilho submetidas aos tratamentos T2 e T3, apresentaram maior número de perfilhos que a testemunha não pulverizada (T1), não havendo diferença entre as doses aplicadas (Tabela 3). Para a variável altura de plantas manteve-se o efeito inicial, observado nas avaliações anteriores, com inibição de altura de plantas pelo glifosato e a maior dose (36 g e.a.ha ${ }^{-1}$ ) causando a maior redução nesta variável (Tabela 3).

$\mathrm{O}$ aumento do perfilhamento das parcelas que receberam glifosato, nesta avaliação, coincide com o observado por Costa et al. (2013) que relataram emissão de novas folhas e de novos perfilhos, por plantas de Urochloa ruziziensis dessecadas a doses de glifosato de 120 até $480 \mathrm{~g}$ e.a.ha ${ }^{-1}$. Por outro lado, a manutenção do efeito de supressão da altura de plantas pelo herbicida parece indicar que esta variável é mais suscetível ao mecanismo de ação do glifosato.

A Tabela 4 mostra os resultados para plantas da forrageira Urochloa ruziziensis no estádio de 2 (dois) perfilhos, submetidas a três doses de glifosato e avaliadas aos 5, 10 e 15 dias após aplicação (DAA) quanto a número de perfilhos e altura de plantas.

TABELA 4. Comparação de médias dos tratamentos das variáveis número de perfilhos e altura de plantas $(\mathrm{cm})$ de Urochloa ruziziensis submetidas, no estádio de 2 perfilhos, ao herbicida glifosato nas dosagens de $0 \mathrm{~g}$ e.a.ha ${ }^{-1} ; 54 \mathrm{~g}$ e.a.ha ${ }^{-1}$ e $72 \mathrm{~g}$ e.a.ha ${ }^{-1}$, avaliadas em 3 épocas (5, 10 e 15 DAA) em consórcio com milho resistente ao herbicida. Goiânia-GO. 2018.

\section{DAA}

\begin{tabular}{lcc}
\hline Tratamentos & \multicolumn{2}{c}{ Variáveis } \\
\cline { 2 - 3 } T1 (testemunha) & Número de Perfilhos & Altura de Plantas $(\mathrm{cm})$ \\
\cline { 2 - 3 } T4 (glifosato 54 g e.a.ha $^{-1}$ ) & $3,65 \mathrm{a}$ & $49,35 \mathrm{a}$ \\
T5 (glifosato 72 g e.a.ha $^{-1}$ ) & $3,60 \mathrm{a}$ & $40,88 \mathrm{~b}$ \\
\hline & $3,55 \mathrm{a}$ & $40,64 \mathrm{~b}$ \\
\hline Tratamentos & \multicolumn{2}{c}{ 10 DAA } \\
\hline
\end{tabular}

15 DAA

\begin{tabular}{|c|c|c|}
\hline Tratamentos & \multicolumn{2}{|c|}{ Variáveis } \\
\hline & Número de Perfilhos & Altura de Plantas $(\mathrm{cm})$ \\
\hline T1 (testemunha) & $3,65 \mathrm{a}$ & $64,20 \mathrm{a}$ \\
\hline T4 (glifosato $54 \mathrm{~g}$ e.a.ha ${ }^{-1}$ ) & $3,36 \mathrm{a}$ & $36,55 \mathrm{~b}$ \\
\hline T5 (glifosato $72 \mathrm{~g}$ e.a.ha ${ }^{-1}$ ) & $3,25 \mathrm{a}$ & $35,64 \mathrm{~b}$ \\
\hline
\end{tabular}

Médias seguidas de mesma letra dentro da mesma data de avaliação não diferem entre si pelo teste de Tukey a $5 \%$ de probabilidade. 
Aos 5 DAA verificou-se, para a variável número de perfilhos, que os tratamentos T4 (glifosato a $54 \mathrm{~g}$ e.a.ha ${ }^{-1}$ ) e T5 (glifosato a $72 \mathrm{~g}$ e.a.ha ${ }^{-1}$ ) não diferiram da testemunha não pulverizada T1, não havendo redução do perfilhamento de plantas pela aplicação do herbicida (Tabela 4). Ao mesmo tempo, para a variável altura de plantas, os tratamentos T4 e T5 diferiram da testemunha T1, mas não entre si, havendo igual redução na altura de plantas pela aplicação das doses de herbicida (Tabela 4).

Os resultados indicaram maior eficiência inicial do herbicida glifosato na redução da altura de plantas do que na redução do perfilhamento, neste estádio de desenvolvimento da forrageira, o que poderia ser explicado pela inibição da atividade de auxinas e manutenção da atividade de giberelinas, pela ação inibitória do mecanismo de ação do glifosato sobre o aminoácido triptofano, precursor da síntese de auxinas (VIDAL et al., 2014).

A ausência de diferença entre os tratamentos, para número de perfilhos das plantas, indicou que as doses testadas seriam insuficientes para suprimir o desenvolvimento desta variável, o que de certo modo, contraria o observado por Silva et al. (2016) que afirmaram que por tratarem-se de plantas sem propagação vegetativa, portanto com menos reservas, mesmo subdosagens de glifosato reduziriam o desenvolvimento de Urochloa ruziziensis.

Em contrapartida, a boa supressão da altura da forrageira poderia ser explicada pela ação do glifosato na redução dos níveis de auxina dos vegetais, pela inibição da síntese de seu precursor o triptofano, o que reduziria o crescimento vertical das plantas tratadas, conforme Vidal et al. (2014) e Rodrigues e Almeida (2018).

Aos 10 DAA não se observou diferença entre os tratamentos para número de perfilhos e as parcelas dos tratamentos T4 e T5 apresentaram o mesmo comportamento do perfilhamento de plantas que a testemunha $T 1$, não havendo, mesmo, aumento do número de perfilhos em relação à primeira avaliação (Tabela 4). Para a variável altura de plantas manteve-se o padrão de resposta aos tratamentos da primeira avaliação com os tratamentos T4 e T5 diferindo da testemunha, mas não entre si, suprimindo, igualmente, a altura de plantas (Tabela 4).

A avaliação feita aos 15 DAA não apresentou variação em relação às avaliações anteriores, não havendo diferença entre os tratamentos sobre as parcelas para a variável número de perfilhos e a altura de plantas sendo reduzida, igualmente, pelos tratamentos T4 e T5 (Tabela 4).

A não redução do número de perfilhos, nesta avaliação, parece indicar a insuficiência das doses testadas para a supressão desta variável da forrageira, uma vez que o tempo decorrido da aplicação já teria proporcionado o intervalo ótimo para a ação do glifosato, conforme o relatado por Machado et al. (2018) que observaram boa eficiência de glifosato na redução de perfilhos de Urochloa ruziziensis apenas aos 14 DAA para plantas dessecadas para formação de palhada.

No mesmo sentido Brighenti et al. (2011) recomendaram que os trabalhos com aplicação de glifosato para supressão de Urochloa ruziziensis fossem avaliados em intervalos inferiores a 25 DAA. Lima et al. (2014) relataram bom efeito de glifosato já aos 7 DAA em estudo da eficiência deste herbicida na dessecação da forrageira, o que poderia ser atribuído ao rápido efeito supressivo sobre o metabolismo vegetal, presente nos herbicidas inibidores de EPSPs (VIDAL et al., 2014). 
A manutenção do efeito de supressão da altura de plantas da forrageira, pelos tratamentos T4 e T5, aos 15 DAA, coincide com o relatado por Silveira et al. (2017) que estudando o efeito de doses de glifosato sobre Urochloa ruziziensis, afirmaram que 0 efeito de glifosato sobre o sistema fotossintético desta forrageira se intensificaria a partir de 15 d.a.a., devido ao efeito cumulativo da redução de transferência de energia do sistema de captação de luz para os centros de reação do Fotossistema II, o que reduziria a capacidade de regeneração das rotas metabólicas afetadas.

\section{CONCLUSÃO}

As doses de herbicida utilizadas não reduziram o perfilhamento de Urochloa ruziziensis nos dois estádios de desenvolvimento avaliados.

As doses testadas reduziram a altura de plantas da forrageira em ambos os estádios de desenvolvimento avaliados e glifosato a $36 \mathrm{~g}$ e.a.ha ${ }^{-1}$ apresentou o maior efeito na redução da altura de plantas no estádio de 1 perfilho.

\section{AGRADECIMENTOS}

Ao Engenheiro Agrônomo Lamartine Nogueira Gonzaga, funcionário da UFG, pela grande ajuda na execução deste trabalho de pesquisa.

\section{REFERÊNCIAS}

ABBAS, T.; NADEEM, M.A.; TANVEER, A.; ALI, H.H.; SAFDAR, M.E.; ZOHAIB, A.; FAROOQ, N. Exploring the herbicidal and hormetic potencial of allelopathic crops against fenoxaprop-resistant Phalaris minor. Planta Daninha, 36:e018176368. 2018. Disponível em : <https://dx.doi.org/10.1590/S0100-83582018360100056>. doi: $10.1590 /$ S0100-83582018360100056

BRIGHENTI, A.M.; SOUZA SOBRINHO, F.; ROCHA, W.S.D.; MARTINS, C.E.; DEMARTINI, D.; COSTA, T.R. Suscetibilidade diferencial de espécies de braquiária ao herbicida glifosato. Pesquisa Agropecuária Brasileira, v. 46, n.10, p. 12411246. 2011. Disponível em: <https://www.scielo.br/pdf/pab/v46n10/46v10a17.pdf>.

COSTA, N.V.; PERES, E.J.L.; RITTER, L.; SILVA, P.V.; FEY, E. Avaliação do glifosato e paraquat no manejo da Brachiaria ruziziensis. Revista Brasileira de Herbicidas, 12 (1), 31-38. 2013. Disponivel em: <https://dx.doi.org/10.7824/rbh.v12i1.179>. doi: 10.7824/rbh.v12i1.179

DIAS, R.C.; SANTOS, M.V.; FERREIRA, E.A.; BRAZ, T.G.S.; FIGUEIREDO, L.V.; CRUZ, P.J.R.; SILVA, L.D. Phytosociology in degraded and renewed pastures in agrosilvopastoral systems. Planta Daninha, 36:e018174800. 2018. Disponível em: < https:// dx.doi.org/10.1590/S0100-83582018360100075>. doi: 10.1590/S010083582018360100075

FERREIRA, L.R.; QUEIROZ, D.S.; MACHADO, A.F.L.; FERNANDES, L.O. Formação de pastagens em sistemas de integração. Informe Agropecuário, v. 28, n. 240, p. 52-62. 2007. Disponível em: <https://www.ia_240.pdf>.

FRANCHINI, J.C.; BALBINOT JÚNIOR, A.A.; DEBIASI, H.; CONTE, O. Crescimento da soja influenciado pela adubação nitrogenada na cultura, pressão de pastejo e épocas de dessecação de Urochloa ruziziensis. Revista Agro@mbiente On-line, v. 
9, n. 2, p. 129-135. 2015. Disponível em: <http://dx.doi.org/10.18227/19828470ragro.v9i2.2611>. doi: 10.18227/1982-8470 ragro.v9i2.2611

FREITAS, M.A.M.; SILVA, D.V.V.; SOUZA, M.F.; SILVA, A.A.; SARAIVA, D.T.; FREITAS, M.M.; CECCON, P.R.; FERREIRA, L.R. Levels of nutrientes and grain yeld of maize intercropped with signalgrass (Brachiaria) in different arrangements of plants. Planta Daninha, v. 33, n. 1, p. 49-56. 2015. Disponível em : < https://www.scielo.br/pdf/pd/v33n1/0100-8358-pd-33-01-00049.pdf>.

JASPER, S.P.; PICCOLI JR., G.J.; VELINI, E.D.; SOUSA, S.F.G.; CARBONARI, C.A. Management of maize stover with underdoses rates of glyphosate applications in notillage. Planta Daninha, v. 33, n. 3, p. 543-550. 2015. Disponível em: < https:// dx.doi.org/10.1590/S0100-83582015000300016>. doi: 10.1590/S010083582015000300016

LIMA, S.F.; TIMOSSI, P.C.; ALMEIDA, D.P.; SILVA, U.R. Weed suppression in the formation of Brachiarias under three sowing methods. Planta Daninha, v. 32, n. 4, p. 699-707. 2014. Disponível em: <https://www.scielo.br/pdf/pd/v32n4/04-pdf>.

MACHADO, L.A.Z.; COMUNELLO, É.; CECATO, U.; CONCENÇO, G. Susceptibillity of perennial tropical forage plants to glyphosate herbicide in integrated crop-livestock farming systems. Planta Daninha, 36:e018160687. 2018. Disponível em: < https:// dx.doi.org/10.1590/S0100-83582018360100105>. doi: 10.1590/S010083582018360100105

QUEIROZ, R.F.; CHIODEROLI, C.A.; FURLANI, C.E.A.; HOLANDA, H.V.; ZERBATO, C. Maize intercropped with Urochloa ruziziensis under no-tillage system. Pesquisa Agropecuária Tropical, v. 46, n. 3, p. 238-244. 2016. Disponível em: <http://dx.doi.org/10.1590/1983-40632016v4640464>. doi: 10.1590/1983$40632016 v 4640464$

RODRIGUES, B.N.; ALMEIDA, F.S. Guia de herbicidas. 7. ed. Londrina: Ed. Autores, 2018. 764 p.

SANTOS, N.C.B.; MATEUS, G.P.; BARBAROTO, K.; SILVA, G.G. Inoculação de milho e Urochloa ruziziensis em consórcio intercalar. Nucleus, Edição Especial, p. 63-72. 2018. Disponível em: <http://dx.doi.org/10.3738/1982.2278.3005>. doi: $10.3738 / 1982.2278 .3005$

SÃO MIGUEL, A.S.D.C.; PACHECO, L.P.; SOUZA, E.D.; SILVA, C.M.R.; CARVALHO, I.C. Cover crops in the weed management in soybean culture. Planta Daninha, 36:e018172534. 2018. Disponível em: < https:// dx.doi.org/10.1590/S010083582018360100072>. doi: 10.1590/S0100-83582018360100072

SILVA, D.V.; FREITAS, M.A.M.; SOUZA, M.F.; QUEIROZ, G.P.; MELO, C.A.D;, SILVA, A.A.; FERREIRA, L.R.; REIS, M.R. Glyphosate herbicide use in Urochloa brizantha management in intercropping with herbicide-resistant maize. Planta Daninha, v. 34, n. 1, p. 133-141. 2016. Disponível em: <https:// 
SILVA, P.I.B.; FONTES, D.R.; MORAES, H.M.F.; GONÇALVES, V.A.; SILVA, D.V.; FERREIRA, L.R.; FELIPE, R.S. Crescimento e rendimento do milho e da braquiária em sistema consorciado com diferentes manejos de plantas daninhas. Planta Daninha, v, 32, n. 2, p. 301-309. 2014. Disponível em: < https://www.scielo.br/pdf/pd/v32n2/v32n2a07.pdf >.

SILVEIRA, R.R.; SANTOS, M.V.; FERREIRA, E.A.; SANTOS, J.B.; SILVA, L.D. Chlorophyll fluorescence in Brachiaria decumbens and Brachiaria ruziziensis submited to herbicides. Planta Daninha, 35:e017165099. 2017. Disponível em : < https://dx.doi.org/10.1590/S0100-83582017350100042>. doi: 10.1590/S010083582017350100042

THE R CORE TEAM. R: A language and environment for statistical computing. R Foundation for Statistical Computing. Version 3.5.3. Vienna, Austria. 2018. Disponível em: < http://www.R-project.org $>$.

TIMOSSI, P.C.; TEIXEIRA, I.R.; LIMA, S.F.; TELLES, T.F.M. Weed management with Urochloa ruziziensis in three sowing methods. Planta Daninha, 36:e018142087. 2018. Disponível em: <https://dx.doi.org/10.1590/S0100-83582018360100060>. doi: $10.1590 / \mathrm{S} 0100-83582018360100060$

VIDAL, R.A.; MEROTTO JR., A.; SCHAEDELER, C.E.; LAMEGO, F.P.; PORTUGAL, J.; MENENDES, J.; KOZLOWSKI, L.A.; TREZZI, M.M.; PRADO, R. Mecanismos de ação dos herbicidas. In: MONQUERO, P.A. (Org.). Aspectos da biologia e manejo das plantas daninhas. São Carlos: Rima, 2014. p. 235-255. 